\title{
A web-based dietary intervention in early pregnancy and neonatal outcomes: A randomized controlled trial
}

\author{
Rachel AK Kennedy \\ Technological University Dublin, rachel_kennedy@live.ie \\ C.M.E. Reynolds \\ University College Dublin \\ S. Cawley \\ University College Dublin
}

See next page for additional authors

Follow this and additional works at: https://arrow.tudublin.ie/scschbioart

Part of the Dietetics and Clinical Nutrition Commons, Maternal and Child Health Commons, and the Women's Health Commons

\section{Recommended Citation}

R A K Kennedy, C M E Reynolds, S Cawley, E O'Malley, D M McCartney, M J Turner, A web-based dietary intervention in early pregnancy and neonatal outcomes: a randomized controlled trial, Journal of Public Health, Volume 41, Issue 2, June 2019, Pages 371-378, DOI: 10.1093/pubmed/fdy117

This Article is brought to you for free and open access by the School of Biological Sciences at ARROW@TU Dublin. It has been accepted for inclusion in Articles by an authorized administrator of ARROW@TU Dublin. For more information, please contact arrow.admin@tudublin.ie, aisling.coyne@tudublin.ie,gerard.connolly@tudublin.ie. Funder: Technological University Dublin 
Authors

Rachel AK Kennedy, C.M.E. Reynolds, S. Cawley, E. O'Malley, D.M. McCartney, and M.J. Turner

This article is available at ARROW@TU Dublin: https://arrow.tudublin.ie/scschbioart/297 


\title{
A web-based dietary intervention in early pregnancy and neonatal outcomes: a randomized controlled trial
}

\section{R.A.K. Kennedy ${ }^{1,2}$, C.M.E. Reynolds ${ }^{1}$, S. Cawley ${ }^{1,2}$, E. O'Malley ${ }^{1}$, D.M. McCartney ${ }^{2}$, M.J. Turner ${ }^{1}$}

${ }^{1}$ UCD Centre for Human Reproduction, Coombe Women and Infants University Hospital, Cork Street, Dublin 8, Ireland

${ }^{2}$ School of Biological Sciences, Dublin Institute of Technology, Kevin Street, Dublin 8, Ireland

Address correspondence to Rachel Kennedy, E-mail: rachel_kennedy@live.ie

\begin{abstract}
Background Maternal nutrition is a determinant of pregnancy outcomes. Few studies have evaluated the potential of online nutrition resources to modify behaviour. This randomized controlled trial aimed to determine whether access to a customized evidence-based nutrition website in pregnancy improved neonatal outcomes.

Methods Women $<18$ weeks gestation were recruited at their convenience. The control group received standard care. In addition to standard care, the intervention group received access to an evidence-based nutrition website, customized to the preferences of pregnant women.

Results Of the 250 women, there were no differences in characteristics between the two groups. Of the women, $91.0 \%$ reported they make a conscious effort currently to eat a healthy diet. However, only $19.6 \%$ met dietary requirements for calcium, $13.2 \%$ for iron, $2.7 \%$ for folate and $2.3 \%$ for iodine. The most popular website section was pregnancy nutrition advice but engagement was not sustained. Access to the website was not associated with any improvement in clinical outcomes $(P>0.05)$.

Conclusions We found that provision of a customized website providing nutrition information, did not improve neonatal outcomes. Future studies should explore whether redesign with website interactivity or embedding information on popular digital platforms sustains women's engagement and modifies dietary behaviour.
\end{abstract}

Keywords e-health, food and nutrition, public health

\section{Introduction}

Epidemiological studies have shown that maternal nutrition is associated with neonatal outcomes. ${ }^{1,2}$ In the developing world, inadequate maternal nutrition is a large contributor to adverse neonatal outcomes such as low birth weight (LBW), small for gestational age (SGA) and preterm birth (PTB)., Conversely, in well-resourced countries, the increasing prevalence of excess maternal nutrition, and resulting complications such as obesity and gestational diabetes mellitus (GDM), is also associated with neonatal health risks such as macrosomia and hypoglycaemia post-delivery. ${ }^{5,6}$ Research has highlighted poor country-specific adherence to nutrition recommendations in developed countries. ${ }^{7}$ Evidence suggests that inappropriate dietary intakes during pregnancy can negatively impact foetal growth and is linked with adverse metabolic profiles of these offspring later in life. ${ }^{4,8}$
A recent review concluded that interventions based on whole foods and dietary patterns may provide more insightful information on pregnancy outcomes. ${ }^{1}$ Thus, delivery of nutrition information to women in pregnancy focusing on a 'whole diet' approach, rather than nutrients in isolation, may improve dietary intakes and consequently improve neonatal outcomes. Technology-supported communications in pregnancy constitute a practical means of delivering evidencebased information to large populations. ${ }^{9,10}$ Research has shown decreasing interest in receiving nutrition information

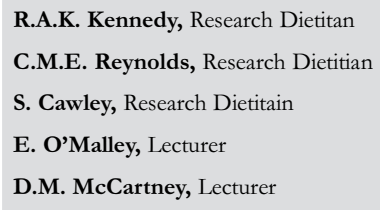

M.J. Turner, Professor 
in the traditional one-to-one format with a healthcare professional and growing interest in receiving information in an online format. ${ }^{11}$ A systematic review found that technologybased communications are a potentially effective means of delivering pregnancy information. However, their effectiveness in generating behavioural and health outcome changes has yet to be confirmed. ${ }^{10}$

Research has highlighted that the majority of pregnant women, irrespective of their sociodemographic and clinical circumstances, used web-based resources for information on nutrition. ${ }^{12}$ However, the web-based resources used were mainly commercial with little use of academically-supported resources. There is a dearth of RCTs examining whether web-based delivery of nutrition interventions provided to women as they present for antenatal care improves neonatal outcomes. Therefore, we designed a web-based resource customized to women's reported preferences in pregnancy and examined its impact on clinical outcomes. ${ }^{12}$

This randomized controlled trial aimed to examine whether access to a customized evidence-based nutrition website from women's first antenatal visit improved neonatal outcomes.

\section{Methods}

Women were recruited conveniently between October 2015 and January 2017 as they presented for antenatal care in a large University Hospital. Women were enrolled in a singleblinded randomized controlled trial. Women who were $<18$ weeks gestation and who had a singleton ongoing pregnancy were included. Women who did not understand English, who were $<18$ years of age, who did not have an email address or did not have internet access were excluded. Informed written consent was obtained.

Women were randomly allocated to either the control group, which received standard care alone or to the intervention group, which received exclusive access to a nutrition website in addition to standard care. Standard care included written Hospital information leaflets on healthy eating in pregnancy, based on evidenced-based guidelines. The intervention group was advised to complete their baseline login to the website at the recruitment visit, or as soon as possible afterwards to allow the researcher to approve login access.

A nutrition and lifestyle website, 'OptiMUM Nutrition' was developed in September 2015 (by RK), using the website building platform Wix.com. Features added to the website included a unique participant login code to ensure only the intervention group had access to the website, mobile optimization features, search features and content tags (i.e. keywords to identify content) to aid user navigation of the website. The analytical software, web-stat.com, was embedded in the site to assess women's usage patterns. The website layout, features and content pages were customized to women's reported preferences. ${ }^{12}$

The website's main landing page included the researchers' contact information, in addition to information on the background purpose of the study. Content pages for the website included recipes, nutrition advice, and lifestyle advice. All recipes added to the website were checked for suitability in pregnancy (by RK). All nutrition information included in the website was based on national clinical guidelines for nutrition in pregnancy and evidence-based resources generated through the Irish Nutrition and Dietetic Institute. ${ }^{13,14}$

Women's height was measured to the nearest centimetre and weight was measured to the nearest $0.1 \mathrm{~kg}$ (Tanita MC 180, Tokyo, Japan). Body Mass Index (BMI) was calculated. Women completed a self-administered semi-supervised paper-based questionnaire. The questionnaire contained questions regarding women's attitudes and beliefs for example perceptions of own diet, barriers to healthy eating, stage of dietary change, future salience and health locus of control and these were derived from previous studies. ${ }^{15-20}$

To assess habitual food and nutrient intakes the researcher (RK) conducted an in person fully supervised four-day, retrospective diet history with all women. The diet history contained two weekdays and two weekend days of the previous week. All portion sizes were fully quantified using standard household measures (e.g. cup, teaspoon etc.).

Maternal and neonatal outcomes were computerized routinely after delivery. Birth weight was measured by a midwife and documented within 30 min of birth. All women had a dating ultrasound to confirm gestational age and gestational age at birth was documented following delivery.

Research has shown a positive relationship between dietary quality and birth weight. ${ }^{21}$ Sample size was calculated (PS Power and Sample Size Calculations, Version 3.0, January 2009) based on a significance level of $5 \%$, power of $80 \%$ and birth weight standard deviation of $470 \mathrm{~g}$ to determine a $250 \mathrm{~g}$ difference in birth weight between the intervention and control groups. ${ }^{22}$ This indicated that 112 participants were required (56 per arm). Due to high attrition rates experienced in previous technology-based studies in pregnancy, an attrition rate of $55 \%$ was selected, and to allow for 1:1 randomization, a total of 250 participants was required (125 per arm). ${ }^{23,24}$ Randomization software (Graphpad Software (C), USA) was used to generate the randomization sequence. An individual independent of the trial placed the software generated group allocations into sequentially numbered, opaque, sealed envelopes to ensure the researcher remained blinded prior to screening and recruitment of participants. 
Data analysis was carried out using SPSS version 22.0 (IBM Corporation, Armonk, New York). Continuous variables were assessed for normality by determination of the kurtosis and skewness of the distribution, visual inspection of their histograms and assessment of their Kolmogorov-Smirnov statistics. Descriptive statistics were used to describe the general characteristics of the study participants. Differences in categorical variables between the control and intervention groups were analysed using cross-tabulation with Chi-square tests for independence. Differences in continuous variables were assessed using an independent samples $t$-test.

Maternal dietary data from the diet histories were entered into Nutritics Version 3.7 (University Edition) to convert the reported food intakes into nutrient intakes. Average daily nutrient intakes for the four-day period were then calculated using this software. The food composition tables used in Nutritics are derived from McCance and Widdowson's Food Composition Tables seventh edition, and all supplemental volumes (McCance and Widdowson 2002). ${ }^{25}$ Women were dichotomized into those meeting and not meeting recommended dietary intake guidelines based on the European Food Safety Authority (EFSA) guidelines. ${ }^{26,27}$

A $P$ value of $<0.05$ was considered statistically significant. This study received ethical approval from the Hospital's Research Ethics Committee and the Dublin Institute of Technology Research Ethics Committee.

\section{Results}

Of the 415 women who were screened for eligibility, 63 women did not meet the inclusion criteria. A further 47 women declined to participate in the study. Of the women eligible to participate, $86.6 \%$ agreed $(n=305)$, however, 55 of these did not return after their scan to complete enrolment. A total of 250 women were randomized to the control or intervention arm of the study.

The commonest reason for declining to participate was that they were 'not interested' $(n=35)$. Others included: they did not have sufficient time to participate $(n=4)$, they believed they knew enough about nutrition already $(n=4)$ and finally, one woman said she had participated in research on her previous pregnancy. The characteristics of both arms of the study population are compared in Table 1.

Table 1 also outlines women's behavioural and attitudinal characteristics. In relation to self-reported stage of change, of those in the intervention group, more women $<30$ years of age were in the action phase $(36.7 \%, n=11 / 30)$ compared to those $\geq 30$ years of age $(16.2 \%, n=12 / 74)(P=$ $0.02)$, however, $66.2 \%(n=49 / 74)$ of women $\geq 30$ years were in the maintenance phase compared to only $26.7 \%(n=8 / 30)$ of women $<30$ years of age $(P<0.001)$. Sample size within the other subgroups was too small to perform analyses.

Of the women in the intervention group, those $\geq 30$ years of age were more likely to report being fully committed to making dietary changes $(74.6 \%, n=47 / 63)$, compared to those $<30$ years $(53.3 \%, n=16 / 30) \quad(P=0.04)$. Additionally, women $\geq 30$ years of age were more likely to report they were confident to keep dietary changes going $(78.1 \%, n=50 / 64)$ compared to those $<30$ years of age $(50.0 \%, n=14 / 28)(P=0.007)$. Interestingly, women who were obese were more likely to report if they decided to make changes, they were confident they could keep them going $(90.5 \%, n=19 / 21)$ compared with those who were not obese $(63.4 \%, n=45 / 71)(P=0.02)$. These factors did not differ by parity, smoking status, taking folic acid preconceptionally or planning the pregnancy $(P>0.05)$.

Additionally, of the women in the intervention group, $27.3 \%(n=6 / 22)$, women without a third level education reported agreeing with the statement 'Good health is determined by chance', compared to only $9.0 \%(n=6 / 67)$ of women with a third level education $(P=0.03)$. This did not differ by parity, smoking status, taking folic acid preconceptionally or planning the pregnancy $(P>0.05)$.

A total of 219 food diaries were conducted. Table 2 outlines the proportion of women meeting macronutrient and micronutrient recommendations outlined by EFSA. ${ }^{26}$

Fig. 1 depicts women's engagement with the OptiMUM Nutrition website over the study period. A total of 125 women were allocated to the intervention group, however, only 118 women completed the baseline login to the website. A total of 40 repeat visits were recorded (return rate $33.9 \%$ ). The website section that received the most views was pregnancy nutrition advice (78 views) with an average stay of $15.2 \mathrm{~min}$, followed by recipes (64 views, $27.0 \mathrm{~min}$ average stay), lifestyle advice (43 views, $17.7 \mathrm{~min}$ average stay) and finally the chat forum (12 views, $0.7 \mathrm{~min}$ average stay).

The time of day the site was most accessed at was 11:0013:00, with the highest number of 40 visitors at this time. This was followed by 16:00-18:00 which received 29 visitors. Tuesdays were the most popular day for women to access the website with the highest number of visitors reaching 34, this was followed by Thursdays $(n=27)$, and Wednesdays $(n=23)$, respectively.

In relation to maternal outcomes, there was no difference in GDM diagnosis between the control group $(n=10 / 114$, $8.4 \%)$ and the intervention group $(n=4 / 114,3.4 \%)(P=$ $0.17)$. There was also no difference between the control $(n=$ $8 / 117,6.7 \%)$ and the intervention group $(n=9 / 116,7.8 \%)$ for Caesarean Section (emergency) rates $(P=0.76)$. Finally, there was no difference in the proportion of women who 
Table 1 Maternal characteristics $(n=250)$

\begin{tabular}{|c|c|c|c|c|c|c|c|}
\hline \multirow[t]{2}{*}{ Study characteristics } & \multicolumn{2}{|c|}{ Total $(\mathrm{n}=250)$} & \multicolumn{2}{|c|}{$\begin{array}{l}\text { Control group } \\
(\mathrm{n}=125)\end{array}$} & \multicolumn{2}{|c|}{$\begin{array}{l}\text { Intervention group } \\
(\mathrm{n}=125)\end{array}$} & \multirow[t]{2}{*}{$P *$} \\
\hline & n, Mean & $\%, S D$ & n, Mean & $\%, S D$ & n, Mean & $\%, S D$ & \\
\hline \multicolumn{8}{|l|}{ Age categories (years; $n, \%)$} \\
\hline$<30$ Years & 75.0 & 30.0 & 35.0 & 28.0 & 40.0 & 32.0 & 0.49 \\
\hline$\geq 30$ Years & 175.0 & 70.0 & 90.0 & 72.0 & 85.0 & 68.0 & 0.49 \\
\hline Nulliparas $(n, \%)$ & 113.0 & 45.2 & 63.0 & 50.4 & 50.0 & 40.0 & 0.10 \\
\hline BMI $\left(\mathrm{kg} / \mathrm{m}^{2} ;\right.$ mean, SD) & 26.1 & 5.9 & 25.7 & 5.7 & 26.5 & 6.1 & 0.75 \\
\hline Obesity $(n, \%)$ & 56.0 & 22.4 & 25.0 & 20.0 & 31.0 & 24.8 & 0.36 \\
\hline Smokers $(n, \%)$ & 22.0 & 8.8 & 12.0 & 9.7 & 10.0 & 8.0 & 0.66 \\
\hline Third level education $(n, \%)^{a}$ & 160.0 & 75.1 & 79.0 & 73.9 & 81.0 & 76.4 & 0.66 \\
\hline Alcohol $(n, \%)^{\mathrm{b}}$ & 208.0 & 83.5 & 101.0 & 81.5 & 107.0 & 85.6 & 0.31 \\
\hline Pre-pregnancy FA $(n, \%)^{b}$ & 138.0 & 55.4 & 70.0 & 56.6 & 68.0 & 54.5 & 0.80 \\
\hline Planned pregnancy $(n, \%)$ & 175.0 & 70.3 & 88.0 & 71.0 & 87.0 & 69.6 & 0.89 \\
\hline \multicolumn{8}{|l|}{ Stages of dietary change ${ }^{c}$} \\
\hline Pre-contemplation & 10.0 & 4.7 & 8.0 & 7.3 & 2.0 & 1.9 & - \\
\hline Contemplation & 15.0 & 7.0 & 8.0 & 7.3 & 7.0 & 6.7 & 0.86 \\
\hline Planning & 23.0 & 10.8 & 13.0 & 11.9 & 10.0 & 9.6 & 0.59 \\
\hline Action & 52.0 & 24.4 & 29.0 & 26.6 & 23.0 & 22.1 & 0.45 \\
\hline Maintenance & 105.0 & 49.3 & 48.0 & 44.0 & 57.0 & 54.8 & 0.12 \\
\hline Relapse & 8.0 & 3.8 & 3.0 & 2.8 & 5.0 & 4.8 & - \\
\hline \multicolumn{8}{|l|}{ Attitudinal statements } \\
\hline If I decide to change my diet I'm confident I'll maintain these changes ${ }^{d}$ & 132.0 & 70.2 & 68.0 & 70.8 & 64.0 & 69.6 & 0.85 \\
\hline I have mixed feelings if changing my diet is a priority at the moment $\mathrm{e}^{\mathrm{e}}$ & 28.0 & 15.2 & 15.0 & 16.3 & 13.0 & 14.1 & 0.68 \\
\hline I am fully committed to making dietary changes ${ }^{f}$ & 129.0 & 69.7 & 66.0 & 71.7 & 63.0 & 67.7 & 0.55 \\
\hline I currently make a conscious effort to eat a healthy diet ${ }^{g}$ & 172.0 & 91.0 & 85.0 & 88.5 & 87.0 & 93.8 & 0.23 \\
\hline My health is mainly determined by chance ${ }^{h}$ & 17.0 & 9.1 & 4.0 & 4.3 & 13.0 & 13.8 & - \\
\hline My health is mainly controlled by outside influences ${ }^{i}$ & 8.0 & 4.3 & 5.0 & 5.3 & 3.0 & 3.2 & - \\
\hline My health is under my own control ${ }^{i}$ & 176.0 & 93.6 & 87.0 & 92.6 & 89.0 & 94.7 & 0.55 \\
\hline
\end{tabular}

BMI, Body mass index; FA, Folic acid; SD, standard deviation.

*(between intervention and control).

- Insufficient sample to perform analysis.

a Total population $n=213$, control $n=107$, intervention $n=106$.

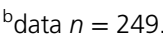

'Total population $n=213$, control $n=109$, intervention $n=104$.

dTotal population $n=188$, control $n=96$, intervention $n=92$.

'Total population $n=184$, control $n=92$, intervention $n=92$.

f Total population $n=185$, control $n=92$, intervention $n=93$.

9Total population $n=189$, control $n=96$, intervention $n=93$.

${ }^{\mathrm{h}}$ Total population $n=187$, control $n=93$, intervention $n=94$.

'Total population $n=188$, control $n=94$, intervention $n=94$.

breastfed exclusively in the control $(n=44 / 119,37.6 \%)$ and intervention group $(n=45 / 116,38.5 \%)(P=0.85)$.

Neonatal delivery data was available on 236 women who met the screening criteria. One woman withdrew, one woman did not have an email address, two women miscarried, three women had twin pregnancies, one woman was over 18 weeks gestation; (which were revealed after screening), three women moved to the UK, two women delivered elsewhere, and one woman had no further data available. Table 3 compares the clinical neonatal outcomes between the control and the intervention group. There were no differences in outcomes between the control and intervention group $(P>0.05)$. 
Table 2 Proportion of women meeting nutritional requirements $(n=219)^{*}$

\begin{tabular}{|c|c|c|c|c|c|c|c|}
\hline \multirow[b]{2}{*}{ Nutrient } & \multicolumn{2}{|c|}{ Total $(\mathrm{n}=219)$} & \multicolumn{2}{|c|}{ Control group $(\mathrm{n}=107)$} & \multicolumn{2}{|c|}{ Intervention group ( $\mathrm{n}=112$ ) } & \multirow[t]{2}{*}{$P$} \\
\hline & $\mathrm{n}$ & $\%$ & $\mathrm{n}$ & $\%$ & $\mathrm{n}$ & $\%$ & \\
\hline Carbohydrate (\% of energy) & 95.0 & 43.4 & 44.0 & 41.1 & 51.0 & 45.5 & 0.30 \\
\hline Protein (\% of energy) $)^{a}$ & 187.0 & 85.8 & 88.0 & 82.2 & 99.0 & 89.2 & 0.14 \\
\hline Fat (\% of energy) & 92.0 & 42.0 & 39.0 & 36.4 & 53.0 & 47.3 & 0.07 \\
\hline Vitamin B12 ( $\mu \mathrm{g})$ & 92.0 & 42.0 & 47.0 & 43.9 & 45.0 & 40.2 & 0.34 \\
\hline Vitamin D $(\mu \mathrm{g})$ & 0.0 & 0.0 & 0.0 & 0.0 & 0.0 & 0.0 & - \\
\hline Vitamin C (mg) & 76.0 & 34.7 & 33.0 & 30.8 & 43.0 & 38.4 & 0.15 \\
\hline Vitamin A $(\mu \mathrm{g})$ & 141.0 & 64.4 & 67.0 & 62.6 & 74.0 & 66.1 & 0.35 \\
\hline Iron (mg) & 29.0 & 13.2 & 15.0 & 14.0 & 14.0 & 12.5 & 0.45 \\
\hline Calcium (mg) & 43.0 & 19.6 & 25.0 & 23.4 & 18.0 & 16.1 & 0.12 \\
\hline lodine $(\mu \mathrm{g})$ & 5.0 & 2.3 & 2.0 & 1.9 & 3.0 & 2.7 & - \\
\hline Folate (DFEs) & 6.0 & 2.7 & 1.0 & 0.9 & 5.0 & 4.5 & - \\
\hline Zinc (mg) & 108.0 & 49.3 & 55.0 & 51.4 & 53.0 & 47.3 & 0.32 \\
\hline
\end{tabular}

DFEs, Dietary folate equivalents.

*nutrition recommendations based on EFSA guidelines 2017.

- Insufficient sample to perform analysis.

aTotal $n=218$, Control group $n=107$, Intervention group $n=111$

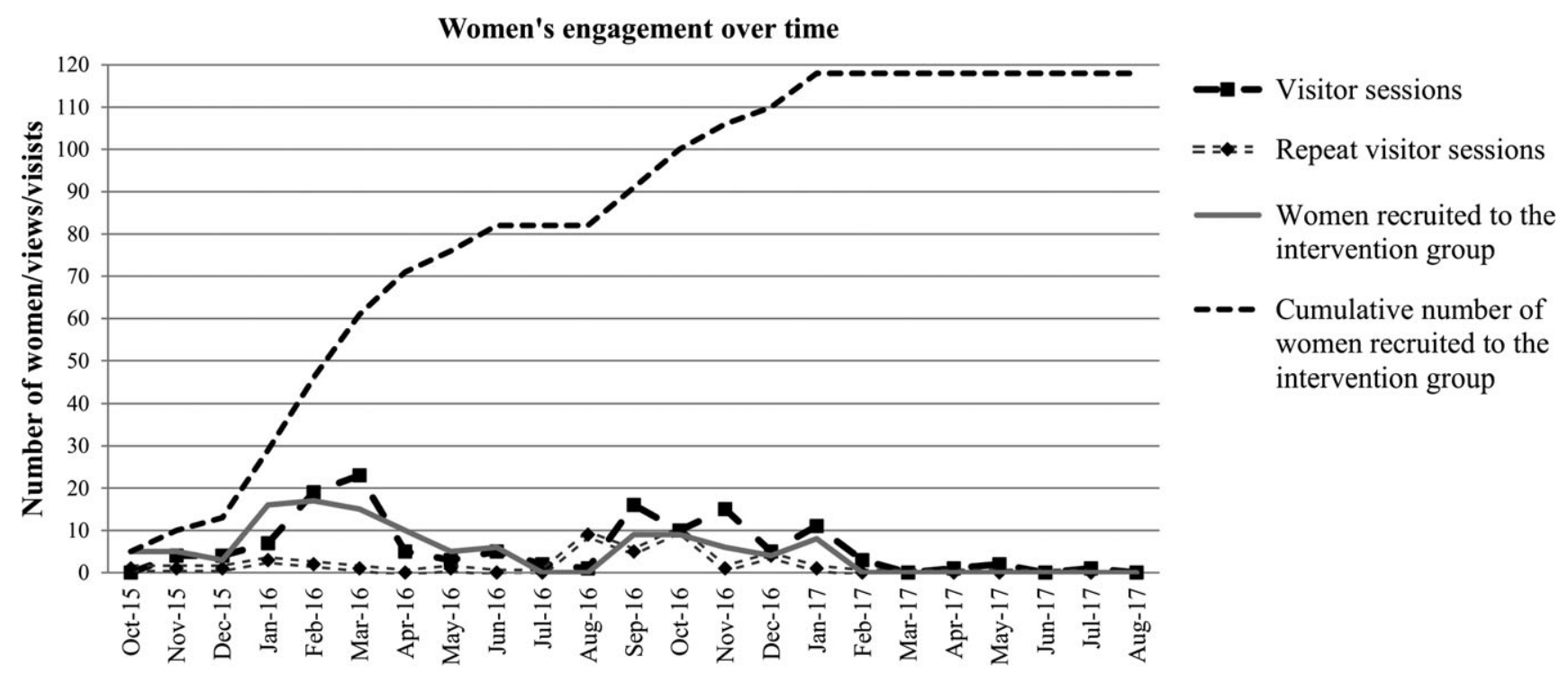

Time

$(*)$

Fig. 1 Women's engagement with the OptiMUM Nutrition website over the study period $(n=118)$. *Recruitment completed by the end of January 2017.

\section{Discussion}

\section{Main finding of this study}

This RCT found that a non-interactive evidence-based website providing nutrition information did not result in sustained maternal engagement as pregnancy advanced. This was despite the fact that women had a high level of access to the internet, and the digital content was customized to meet women's stated preferences. ${ }^{12}$ It is not surprising, therefore, that we found no evidence that provision of evidence-based nutrition information from a web-based resource changed pregnancy outcomes. If dietary behaviour in pregnant women is going to be successfully modified, our findings indicate that further research is needed to identify 
Table 3 Differences between the intervention and control group for maternal and neonatal outcomes $(n=236)$

\begin{tabular}{|c|c|c|c|c|c|}
\hline \multirow[t]{2}{*}{ Neonatal outcomes } & \multicolumn{2}{|c|}{ Control $(\mathrm{n}=119)$} & \multicolumn{2}{|c|}{ Intervention $(\mathrm{n}=117)$} & \multirow[t]{2}{*}{$P$} \\
\hline & $\mathrm{n}$, mean & $S D, \%$ & $\mathrm{n}$, mean & $S D, \%$ & \\
\hline Birth weight (kg; mean, SD) & 3.5 & 0.6 & 3.5 & 0.6 & 0.87 \\
\hline Birth weight $<3.0 \mathrm{~kg}(n, \%)$ & 19.0 & 16.0 & 14.0 & 12.0 & 0.38 \\
\hline Birth weight $>4.0 \mathrm{~kg}(n, \%)$ & 16.0 & 13.4 & 21.0 & 17.9 & 0.34 \\
\hline Head circumference ${ }^{a}(\mathrm{~cm}$; mean, SD) & 35.0 & 1.8 & 35.0 & 1.5 & 0.90 \\
\hline
\end{tabular}

SD, standard deviation.

${ }^{\text {a }}$ control $n=114$, intervention $n=114$.

what digital platforms and techniques will lead to an engagement that will be sustained in a way that may potentially improve fetomaternal clinical outcomes.

This study also identified that the majority of women $(91 \%)$ reported that they make a conscious effort to eat a healthy diet currently, however, there were still notable inadequacies in women's dietary intakes, when compared to the most recent European dietary recommendations. ${ }^{26}$ Thus, while women may believe they are following healthy eating practices, it is evident that women need to be informed of deficits within their dietary intakes and that further education is needed to improve maternal nutrition intakes in early pregnancy.

\section{What is already known on this topic}

A single arm intervention study assessed the use of an online healthy lifestyle programme by pregnant women. The study found only a $17 \%$ enrolment rate $(n=238)$. Furthermore, of the women who enrolled, the majority were well educated $(68 \%)$ and already practiced a healthy lifestyle. Only $9 \%$ of those invited continued to use the programme. ${ }^{23}$ In a larger version of the study $(n=13946)$, which was conducted on a national level in the Netherlands, only $8 \%$ of the population enrolled. Women with lower levels of education were more likely to be inactive users. ${ }^{24}$ However, these studies differed to our intervention in terms of use of existing online resources, rather than creating a web-based resource tailored to women's stated preferences.

A recent Australian study evaluated a smartphone nutrition and physical activity application to provide advice to pregnant women as an adjunct to face-to-face consultations $(n=162)$ (the SNAPP RCT). ${ }^{28}$ Of the 77 women recruited to the intervention group, only $31.2 \%(n=24 / 77)$, reported using the application. The authors reported that the use of the application was poor and there was no improvement in terms of dietary and physical activity patterns.
Online resources are increasingly accessed by women during pregnancy, which may have been a contributing factor to the lack of engagement in our study findings. ${ }^{29-32}$ From a public health perceptive, concerns exist about women's ability to critically appraise the quality of content within online resources. $^{12,33}$ Future research may benefit from collaborations with existing e-Health resources that achieve sustained engagement rates and healthcare professionals for the development and regulation of evidence-based content. This may offset the funding used to create software for further research that continues to see high attrition rates and regulate the quality of information disseminated to women. ${ }^{10,34}$ Additionally, it is necessary to explore, given the lack of success to date in e-Health interventions sustaining women's engagement, if public health resources would be better focused on increasing availability of dietitians to women in early pregnancy with the aim to improve women's nutritional adequacy and perhaps evidence-based online resources used as a source of supportive information rather than to promote behaviour change.

\section{What this study adds}

In this study, nearly $70 \%$ of the intervention group was $\geq 30$ years of age. Our results found that women who are in this age category are more likely to report they are in the maintenance phase of dietary change (than women $<30$ years) -i.e. suggesting they are currently maintaining what they perceive as 'healthy' dietary practices. Furthermore, our results highlighted that this group of women are more likely to report being fully committed to making dietary changes and to report they were confident to keep dietary changes going when compared to those $<30$ years of age. While these women may be interested in nutrition-based interventions, these results may further explain lack of sustained engagement within this cohort as these women may not identify they require further intervention if they believe they are following appropriate dietary practices. Given the dietary inadequacies identified within this study and 
women's perceived healthy dietary practices, this highlights an important public health concern, and women require appropriate nutrition education intervention from early pregnancy to improve dietary adequacy.

A total of 40 repeat visits were recorded, indicating a website return rate of only $33.9 \%$. After completion of recruitment, there were minimal visitor sessions and page views. Additionally, no repeat visits were recorded during this time. The results indicate that visitor sessions and page views correlate with recruitment numbers, which may be a direct result of the initial login women were advised to complete. While the software did not enable tracking of women's unique activity levels, these data suggest that engagement corresponded with baseline login at recruitment. This may explain the low levels of activity recorded with the website after completion of recruitment and the low numbers of repeat visitor sessions. Individuals accessing the internet may become indifferent to stimuli, encounter website navigational difficulties, or become distracted by other online resources such as social media, resulting in disengagement with the intervention and diminished adherence rates. ${ }^{10,35,36}$ Research has indicated that women report accessing information across multiple online resources and reach fatigue of webbased resources quickly. ${ }^{28,37}$

In light of this, our findings on the most commonly accessed site times may provide insights into where communication may be optimized. This may harness engagement through focusing web-based communication with study participants around times which may be more acceptable to them.

\section{Limitations of this study}

Limitations of the study include the inability to track study participant interaction on an individual level due to the analytical software. However, the trends identified in this study are consistent with the literature. A further limitation was the inability to assess associations with login rates and engagement with maternal sociodemographic characteristics. Another limitation was the inability to assess or control if women were engaging with other nutrition-based resources during pregnancy, which may have influenced engagement rates with our website. Finally, the study may not have had sufficient powering for the secondary outcomes of the study.

Randomization was successful as the control and intervention group did not differ in terms of their characteristics. The website was customized, based on a previous study in the same Hospital to ensure the features within the website were tailored to women's preferences. ${ }^{12}$ Additionally, an analytical software was used to record women's engagement, rather than self-reporting.

\section{Acknowledgements}

We would like to acknowledge with gratitude, Dublin Institute of Technology for partly funding this work through a Fiosraigh scholarship to authors RAKK and DMC. We would also like to acknowledge and express thanks to all participants who took part in this study.

\section{References}

1 Grieger JA, Clifton VL. A review of the impact of dietary intakes in human pregnancy on infant birthweight. Nutrients 2015;7: 153-78.

2 Cawley S, Mullaney L, McKeating A et al. An analysis of folic acid supplementation in women presenting for antenatal care. $J$ Public Health $(O x f)$ 2015;38:122-29.

3 da Silva Lopes K, Ota E, Shakya P et al. Effects of nutrition interventions during pregnancy on low birth weight: an overview of systematic reviews. BMJ Glob Health 2017;2:e000389.

4 Morrison JL, Regnault TRH. Nutrition in pregnancy: optimising maternal diet and fetal adaptations to altered nutrient supply. Nutrients 2016;8:342.

5 Castillo-Castrejon M, Powell TL. Placental nutrient transport in gestational diabetic pregnancies. Front Endocrinol (Lausanne) 2017;8:306.

6 Dennedy MC, Dunne F. The maternal and fetal impacts of obesity and gestational diabetes on pregnancy outcome. Best Pract Res Clin Endocrinol Metab 2010;24:573-89.

7 Blumfield ML, Hure AJ, Macdonald-Wicks L et al. Systematic review and meta-analysis of energy and macronutrient intakes during pregnancy in developed countries. Nutr Rev 2012;70:322-36.

8 Barker DJ. In utero programming of chronic disease. Clin Sci (Lond) 1998;95:115-28.

9 O'Higgins A, Murphy OC, Egan A et al. The use of digital media by women using the maternity services in a developed country. Ir Med J 2014;107:313-15.

10 O’Brien OA, McCarthy M, Gibney ER et al. Technology-supported dietary and lifestyle interventions in healthy pregnant women: a systematic review. Eur J Clin Nutr 2014;68:760-66.

11 Bensley RJ, Hovis A, Horton KD et al. Accessibility and preferred use of online Web applications among WIC participants with Internet access. J Nutr Educ Behav 2014;46:S87-92.

12 Kennedy RAK, Mullaney L, Reynolds CME et al. Preferences of women for web-based nutritional information in pregnancy. Public Health 2017;143:71-7.

13 Institute of Obstetrics and Gynaecologists, Royal College of Physicians of Ireland and Directorate of Clinical Strategy and Programmes, Health Service Executive-Clinical Practice Guideline Nutrition for Pregnancy, No. 27, 2013.

14 Irish Nutrition and Dietetic Institute. Healthy Eating During Pregnancy [Internet]. Ireland: INDI, 2015. [Updated 2016 January] Available from: https://www.indi.ie/fact-sheets/fact-sheets-onwomen-s-health/545-healthy-eating-during-pregnancy.html.

15 Kearney MJ, Kearney JM, Gibney MJ. Methods used to conduct the survey on consumer attitudes to food, nutrition and health on 
nationally representative samples of adults from each member state of the European Union. Eur J Clin Nutr 1997;51:S3-7.

16 Kearney JM, Kearney MJ, McElhone S et al. Methods used to conduct the pan-European Union survey on consumer attitudes to physical activity, body weight and health. Public Health Nutr 1999;2:79-86.

17 Allen D, Newsholme HC Attitudes of Older EU Adults to Diet, Food and Health: a Pan-EU Survey Campden and Chorleywood Food Research Association Group. No 174, 2003.

18 Prochaska JO, DiClemente CC. Stages and processes of self-change of smoking: toward an integrative model of change. J Consult Clin Psychol 1983;51:390-95.

19 Wardle J, Steptoe A. Socioeconomic differences in attitudes and beliefs about healthy lifestyles. J Epidemiol Community Health 2003;57:440—43.

20 Wallston BS, Wallston K, Kaplan GD et al. Development and validation of the health locus of control (HLC) Scale. I Consult Clin Psychol 1976;44:580-85.

21 Rodríguez-Bernal CL, Rebagliato M, Iñiguez CJ et al. Diet quality in early pregnancy and its effects on fetal growth outcomes: the Infancia y Medio Ambiente [Childhood and Environment] Mother and Child Cohort Study in Spain. Am J Clin Nutr 2010;91:1659-66.

22 Hawkes CP, Hourihane JO, Kenny LC et al. Gender-and gestational age-specific body fat percentage at birth. Pediatrics 2011;128:e645-51.

23 van Zutphen M, Milder IE, Bemelmans WJ. Usage of an online healthy lifestyle program by pregnant women attending midwifery practices in Amsterdam. Prev Med 2008;46:552-57.

24 Bot M, Milder IE, Bemelmans WJ. Nationwide implementation of Hello World: a Dutch email-based health promotion program for pregnant women. J Med Internet Res 2009;11:24.

25 McCance RA, Widdowson EM. Food Standards Agency McCance and Widdowson's The Composition of Foods, 6th edn. Great Britain: Royal Society of Chemistry, 2002.

26 European Food Safety Authority, Dietary Reference Values for nutrients. Summary report. EFSA supporting publication, No 92, 2017.
27 Mullaney L, Cawley S, Kennedy R et al. Maternal nutrient intakes from food and drinks consumed in early pregnancy in Ireland. J Public Health (Oxf) 2017;39:754-62.

28 Dodd JM, Louise J, Cramp C et al. Evaluation of a smartphone nutrition and physical activity application to provide lifestyle advice to pregnant women: The SNAPP randomised trial. Matern Child Nutr 2017;14:e12502.

29 Lagan BM, Sinclair M, Kernohan WG. A web-based survey of midwives' perceptions of women using the Internet in pregnancy: a global phenomenon. Midwifery 2011;27:273-81.

30 McDaniel BT, Coyne SM, Holmes EK. New mothers and media use: associations between blogging, social networking, and maternal well-being. Matern Child Health J 2012;16:1509-17.

31 Tripp N, Hainey K, Liu A et al. An emerging model of maternity care: smartphone, midwife, doctor? Women Birth 2014;27:64-7.

32 Terry K Number of Health Apps Soars, but Use Does Not Always Follow [Internet]. Medscape, 2015. [Updated 2018 March 15]. Available from: http://www.medscape.com/viewarticle/851226.

33 Kodama S, Saito K, Tanaka S et al. Effect of web-based lifestyle modification on weight control: a meta-analysis. Int J Obes (Lond) 2012;36:675-85.

34 Neuhauser L, Kreps GL. Rethinking Communication in the E-health Era. J Health Psychol 2003;8:7-23.

35 Rodger D, Skuse A, Wilmore M et al. Pregnant women's use of information and communications technologies to access pregnancyrelated health information in South Australia. Aust J Prim Health 2013;19:308-12.

36 Lagan BM, Sinclair M, Kernohan WG. Internet use in pregnancy informs women's decision making: a web-based survey. Birth 2010; 37:106-15.

37 Burke LE, Sereika SM, Music E et al. Using instrumented paper diaries to document self-monitoring patterns in weight loss. Contemp Clin Trials 2008;29:182-93. 